\title{
Systems Biotechnology: an Emerging Trend in Metabolic Engineering of Industrial Microorganisms
}

\author{
Chellapandi $\mathbf{P}^{1 *}$, Sivaramakrishnan $\mathrm{S}^{2}$ and Viswanathan M.B ${ }^{3}$ \\ ${ }^{1}$ Department of Bioinformatics, School of Life Sciences, Bharathidasan University, Tiruchirappalli-620024, Tamilnadu, India \\ ${ }^{2}$ Department of Biotechnology, School of Life Sciences, Bharathidasan University, Tiruchirappalli-620024, Tamilnadu, India \\ ${ }^{3}$ Department of Plant Sciences, School of Life Sciences, Bharathidasan University, Tiruchirappalli-620024, Tamilnadu, India
}

\begin{abstract}
The improvement of production processes to achieve commercially viable production levels is a prerequisite to any bioprocess. Currently, production strains are enhanced using a combination of random and targeted approach. By combining metabolomics technology and genome data analysis, it is possible to replace empirical target-selection strategies with a more scientific approach. All steps of biotechnological development, from up-stream and mid-stream to down-stream processes will benefit significantly by taking systems biotechnological approaches. The prevalence of genome sequence information, in concert with modern molecular biology advances, should have facilitated the easy manipulation of specific genes and pathways for the production of microbial metabolites. A notable success has been made on designing optimized production systems that maximize productivity and minimize raw materials costs for valuable metabolites. A remarkable advantage of this approach up-to-data and its relevant web resources is critically reviewed in this article. Indeed, this alternative approach will not only hopefully be useful for improving the productivity of many meaningful metabolites including antibiotics, enzymes, organic acids, etc. from industrially significant microorganisms but also will ensure correlation of many experimental reliabilities.
\end{abstract}

Keywords: Systems biology; Metabolic engineering; Metabolomics; Metabolic flux; Strain improvement; Genomescale models

\section{Introduction}

The biotechnology potential is increasing exponentially with the identification of organisms, isolation of novel compounds and their pathways, and the molecular and biochemical characterization of cellular components. Improving productivity of commercially viable microbial strains is an important field in biotechnology, especially since wild strains isolated from nature usually produce a low level of products (Bennett and Laswre, 1985; Peberdy and Ferenxy, 1985). A great deal of efforts and resources is therefore attracted to improve wild strains with desirable traits to meet commercial requirements (Hermann, 2004).

In order to produce economically desirable compounds from microbial cell factories, it is generally necessary to retrofit the metabolism since microorganisms are typically evolved for maximizing growth in their natural habitat (Patil et al., 2005). Retrofitting of microbial metabolism has traditionally been done through classical strain improvement that involved random mutagenesis and screening (Peberdy and Ferenxy, 1985). Thereafter, rational design strategies based on genetic engineering have been on increase with success

often referred to as metabolic engineering wherein many experimental and mathematical tools have been developed for introducing direct genetic modifications that will lead to desirable metabolic phenotypes resulting in improved production of desirable compounds or in reduced production of by-products (Stephanopoulos, 2002). Moreover, the metabolic pathways and related regulatory processes form complex molecular and functional interaction networks. One may evaluate the effect of specific genetic modifications through an analysis of the metabolism as a whole in integrative systems approach (Schuster et al., 2000; Tomita et al., 2001; Patil et al., 2005).
A number of researches that has dedicated to systems biology research have been increasing significantly in the recent years, for which biological data are to be analyzed by modeling and simulation of metabolic and regulatory network of organisms (Stelling et al., 2002; Mahadevan et al., 2005). Thus, this review provides a comprehensive summary of current scenario of systems biotechnological advances in bioprocess engineering concerned with available software tools and projects (Table 1 and Table 2).

A central goal of systems biology is the elucidation of cell function and physiology through the integrated use of broad based genomic and physiological data (Kirschne, 2005; Kim et al., 2006). The recent development of omics technology, combined with computational analysis, provides a new avenue for strain improvement and process development by contributing new information extracted from a large number of data, termed as "systems biotechnology" (Sang et al., 2005). The main thrusts include to find out importance of reactions for the overall system performance, detect metabolic network consistency and meaningful functional pathways and energy cycles, and to predict correlated reactions to be co-regulated and network capabilities to attain maximum product yield. This is also to investigate all possible behaviors of a system to

*Corresponding author: P. Chellapandi, Department of Bioinformatics, School of Life Sciences, Bharathidasan University, Tiruchirappalli-620024, Tamilnadu, India, Tel: +91-431-2407071; Fax: +91-431-2407045; E-mail: pchellapandi@gmail.com

Received February 22, 2010; Accepted April 10, 2010; Published April 10, 2010

Citation: Chellapandi P, Sivaramakrishnan S, Viswanathan MB (2010) Systems Biotechnology: an Emerging Trend in Metabolic Engineering of Industrial Microorganisms. J Comput Sci Syst Biol 3: 043-049. doi:10.4172/jcsb.1000054

Copyright: ( $\odot 2010$ Chellapandi $\mathrm{P}$, et al. This is an open-access article distributed under the terms of the Creative Commons Attribution License,which permits unrestricted use, distribution, and reproduction in any medium, provided the original author and source are credited. 
Citation: Chellapandi P, Sivaramakrishnan S, Viswanathan MB (2010) Systems Biotechnology: an Emerging Trend in Metabolic Engineering of Industrial Microorganisms. J Comput Sci Syst Biol 3: 043-049. doi:10.4172/jcsb.1000054

\begin{tabular}{|c|c|c|}
\hline Project name & Web address & Host Institution \\
\hline \multicolumn{3}{|l|}{ In USA } \\
\hline E-Cell & www.e-cell.org & Molecular Sciences Institute \\
\hline Systems Biology Workbench & www.sys-bio.org/ & Keck Graduate Institute \\
\hline BioPAX and Paxtools & www.biopax.org/paxtools/ & Sloan Kettering Institute \\
\hline BioModels Database & www.ebi.ac.uk/biomodels/ & Caltech \\
\hline SBML & http://sbml.org/Main_Page & OHS in HD University \\
\hline SimBiology & www.mathworks.com/ & The MathWorks \\
\hline COPASI & www.copasi.org/ & Virginia Bioinformatics Institute \\
\hline The Computable Plant & www.computableplant.org/ & University of California, Irvine \\
\hline The Virtual Cell & www.ibiblio.org/virtualcell/ & UCHCA \\
\hline \multicolumn{3}{|l|}{ In European countries } \\
\hline Systems Biology Ontology & www.ebi.ac.uk/sbo/ & EMBL-EBI, UK \\
\hline CellDesigner & www.celldesigner.org/ & Oxford Computer Consultants, UK \\
\hline libSBML/SBMLToolbox & http://sbml.org/software/sbmltoolbox/ & University of Hertfordshire, UK \\
\hline SBMLeditor & www.ebi.ac.uk/compneur-srv/SBMLeditor.html & European Bioinformatics Institute, UK \\
\hline Taverna & http://taverna.sourceforge.net/ & University of Manchester, UK \\
\hline SBML Layout Extension & http://otto.bioquant.uni-heidelberg.de/sbml/ & EML Research gGmbH, Germany \\
\hline SIGNALIGN & http://signalignmn.com/ & Bielefeld University, Germany \\
\hline SBML ODE Solver & www.tbi.univie.ac.at/ raim/odeSolver/ & Johann Radon Institute, Austria \\
\hline SBML ODE Solver Library & www.tbi.univie.ac.at/ raim/odeSolver/ & University of Vienna, Austria \\
\hline SOSlib & www.tbi.univie.ac.at/ raim/odeSolver/ & RICAM, Austria \\
\hline GINsim & http://gin.univ-mrs.fr/ & Institute of Marseille-Luminy, France \\
\hline Systems Biology Toolbox & www.sbtoolbox.org/ & Fraunhofer Chalmers Centre, Sweden \\
\hline Institute for Molecular Systems Biology & http://www.imsb.ethz.ch/ & ETH Zurich, Switzerland \\
\hline \multicolumn{3}{|l|}{ In Asian and African countries } \\
\hline BioUML & www.biouml.org/ & Keio University, Japan \\
\hline CellDesigner / ReCSiP & http://recsip.org/ & Institute of Systems Biology, Russia \\
\hline PathwayAnalyser & www.sourceforge.net/projects/pathwayanalyser & Indian Institute of Science, India \\
\hline PySCeS & http://pysces.sourceforge.net/ & $\begin{array}{l}\text { University of Stellenbosch, } \\
\text { South Africa }\end{array}$ \\
\hline Centre for Quantitative Systems Biology & http://cmt.hkbu.edu.hk/ & Hong Kong Baptist University, \\
\hline Center for Systems and Synthetic & http://csb2.web.ym.edu.tw/front/bin/home.phtml & Hong Kong \\
\hline Biology & & National Yang-Ming University, Republic of China \\
\hline Center for Systems Biology and & http://www.csbb.ntu.edu.tw/ & National Taiwan University, \\
\hline Bioinformatics & & Republic of China \\
\hline Systems Biology Laboratory & http://systemsbiology.snu.ac.kr/ & Seoul National University, South Korea \\
\hline
\end{tabular}

Table 1: List of projects with corresponding web and institutional addresses related to systems biotechnology development.

identify the operation modes and understand the functioning of the metabolic system in relation to changes in the environmental conditions and flexibility to switch between different functional modes that are vital for organisms.

\section{Metabolic pathways resources}

Development of metabolic databases derived from the comparative study of metabolic pathways will cater the industrial needs in a more efficient manner to further the growth of systems biotechnology (Kirschne, 2005; Sang et al., 2005; Kim et al., 2006). Some examples of the pathways databases are Kegg, Biochemical pathways, Brenda, Enzyme, Biopathways consortium, IUBMB metabolomic mini-lab, MBBD, NuGO nutritional metabolomics, PathDB, Protein Function and Biochemical Pathways, Proteomic Pathway Project, Reactom, SMRS (Standard Metabolite Reporting Structure), Pathway Hunter Tool, WIT, etc.

A comparative study of different genomes under the wealth of systems biology can reveal some hidden facts, which were either overlooked or they were too complex to understand. Using this approach, the pathways and groups of pathways of different organisms are compared with each other. It has resulted with the advent of binary matrix used to construct a phylogenetic tree, by which the evolutionary role of metabolic pathways in organisms over billions of years deciphers. This process can help the people to produce mutants of interest in their laboratories. One efficient way is to find out the shortest path among the metabolic pathways which is conserved in organisms over millions of years (Ideker et al., 2001; Stephanopoulos et al., 2004; Patil et al., 2004; Patil et al., 2005). This combinatory problem in biochemical network is a challenging task. Thus, such metabolic pathway databases will be helpful for comparative metabolomics and genetic network analysis of industrial microorganisms.

\section{Metabolomics}

Metabolomics is the study of how the metabolic profile of a complete biological system changes in response to environmental stresses. Its goals are to catalog and quantify the myriad small molecules found in the biological fluid under different conditions. Genome-scale stoichiometric models represent the integrated metabolic potential of a microorganism by defining flux-balance constraints that characterize all feasible metabolic phenotypes under steady state conditions (Stephanopoulos et al., 2002; Patil et al., 2004). Since several microbial metabolic networks have evolved towards operation of optimal growth rate (Edwards et al., 2001; Ibaraa et al., 2002). It is often an applied objective function in flux balance analysis (Kauffman et al., 2002; Schwartz et al., 2003). Indeed, the design philosophy underlying OptKnock approach (Burgard et al., 2003) takes advantage of inherent properties of microbial metabolism to drive the optimization of the desired metabolic phenotype. It is an attractive and promising modeling framework for in silico metabolic engineering. Direct relation of genetic algorithm with biological evolution (OptStrain) offers a natural method of choice to identify suitable genetic modifications for improved metabolic phenotypes (Pharkya et al., 2004). Genome sequence goes straight to chemical engineering approaches that will likely become common in the future of biotechnology (Price 
et al., 2003; Galperin, 2004; Christian et al., 2006). Further, the following resources will serve the researchers in retrieving metabolomic information to strengthen systems biotechnology research:

1. Cologn University Bioinformatics Center's Research Group for Molecular Informatics

2. Fiehn Laboratory UC Davis, Genome Center

3. The Golm Metabolome Database - Hosted at Max Planck Institute of Molecular Plant Physiology

4. The Human Metabolome Project - a Project of the Wishart Research Group

5. The Metabolomics Standards Initiative

\section{METLIN Metabolite Database}

7. MeT-RO Metabolomics Rthamsted-UK Center for Plant and Microbial Metabolomic Analysis

8. MDL NMR Metabolomics Database of Linkoping, Sweden

9. NMR Shift DB - Molecular Informatics Software developed by CUBIC

10.PRiMe Platform for Riken Metabolomics

11.SMRS - The Standard Metabolic Reporting Structure

12.SUGABASE - A Carbohydrate-NMR Database from the Netherlands

In the recent years, metabolic flux analysis has become as one of the major tools in metabolic engineering. It is aimed at detailed quantification of all metabolic fluxes in the central

\begin{tabular}{|c|c|c|}
\hline Software tools & Purpose & Ref.\# \\
\hline \multicolumn{3}{|c|}{ Pathway models } \\
\hline Grid layout algorithm & Automatic drawing of biochemical networks & [1] \\
\hline ExtraTrai & A database of Extragenic regions in prokaryotic organisms & [2] \\
\hline GINsim & Qualitative simulation and analysis of regulatory networks & [3] \\
\hline QPath & Querying pathways in a protein-protein interaction network & [4] \\
\hline Cytoscape & Software for integrated models of interaction networks & [5] \\
\hline Multiscale Hy3S & Hybrid stochastic simulation for supercomputers & [6] \\
\hline WholePathwayScope & A comprehensive pathway-based analysis tool & [7] \\
\hline BIOCHAM & Modeling systems and formalizing experimental knowledge & [8] \\
\hline PIANA & Protein interactions and network analysis & [9] \\
\hline Pathway Hunter Tool & Metabolic pathway analysis web service & [10] \\
\hline Tau-leap method & Time accelerated Monte Carlo simulations of biological networks & [11] \\
\hline VisANT & Visual framework for biological networks and modules & [12] \\
\hline Query language & Analysis of biological networks & [13] \\
\hline PATIKA & Collaborative construction and analysis of cellular pathways & [14] \\
\hline \multicolumn{3}{|c|}{ Metabolic Flux analysis } \\
\hline Quadratic program & Decomposing steady-state metabolic flux distributions & [15] \\
\hline Bio-Object & A stochastic simulator for post-transcriptional regulation & [16] \\
\hline Moleculizer & Automatic generation of cellular reaction networks & [17] \\
\hline CADLIVE & Direct link of biochemical networks to dynamic models & [18] \\
\hline BioModels & Database for kinetic models of biochemical and cellular systems & [19] \\
\hline ODE Solver Library & Fast numerical analysis of reaction networks & [20] \\
\hline BioNetGen & Stochastic modeling of biochemical network & [21] \\
\hline BioNetS & Software for rule-based modeling of signal transduction & [22] \\
\hline MetaFluxNet & Quantitative metabolic flux analy & [23] \\
\hline Dynetica & A simulator of metabolite dynamics & [24] \\
\hline MILP-based flux & NMR experimental design strategy for metabolic engineering & [25] \\
\hline \multicolumn{3}{|c|}{ Proteomic analysis } \\
\hline SynTReN & A generator of synthetic gene expression data for design & [26] \\
\hline RegulonDB & Transcriptional regulatory network, and growth conditions & [27] \\
\hline $\mathrm{ABS}$ & Annotated regulatory Binding Sites from orthologous promoter & [28] \\
\hline MaGe & A microbial genome annotation system & [29] \\
\hline ODB & A database of operons prediction & [30] \\
\hline ASAP & Annotating, curating, comparing, and disseminating genomic data & [31] \\
\hline PL Explorer & Protein function prediction & [32] \\
\hline FOOTER & A web tool for phylogenetic footprinting & [33] \\
\hline PromoterPlot & A graphical display of promoter similarities & [34] \\
\hline VAMPIRE suite & Interpretation of gene expression data & [35] \\
\hline TRED & A platform for in silico gene regulation studies & [36] \\
\hline PANTHER DB & Protein families, subfamilies, functions and pathways & [37] \\
\hline TRACTOR_DB & Regulatory networks in gamma-proteobacterial genomes & [38] \\
\hline \multicolumn{3}{|c|}{ Systems biology tools } \\
\hline PAINT & A gene regulatory network and promoter analysis & [39] \\
\hline SB Toolbox & A computational platform for research & [40] \\
\hline Gene Designer & A synthetic biology tool for constructing artificial DNA segments & [41] \\
\hline JCell & Inferring regulatory networks from time series data & [42] \\
\hline WebCell & Kinetic modeling and dynamic simulation of cellular networks & [43] \\
\hline SBMLToolbox & Metabolic simulation & [44] \\
\hline SBW & System simulation software & [45] \\
\hline SimBio & The development of detailed cell models & [46] \\
\hline Grid cellware & A tool for modelling and simulating cellular processes & [47] \\
\hline OptStrain & A multi-algorithmic software for computational systems biology & [48] \\
\hline Cellware & Qualitative simulation of genetic regulatory networks & [49] \\
\hline GNAnalyzer & System simulation tools & [50] \\
\hline BioSPICE & Software environment for whole-cell simulation & [51] \\
\hline A-Cell & Construction of biochemical reaction models & [52] \\
\hline E-CELL & A framework for redesign of microbial production systems & [53] \\
\hline
\end{tabular}

Table 2: List of recent systems biotechnology software tools with their respective applications. 
Citation: Chellapandi P, Sivaramakrishnan S, Viswanathan MB (2010) Systems Biotechnology: an Emerging Trend in Metabolic Engineering of Industrial Microorganisms. J Comput Sci Syst Biol 3: 043-049. doi:10.4172/jcsb.1000054

metabolism of a microorganism to obtain a flux map that shows the distribution of anabolic and catabolic fluxes over the metabolic network. It will help to judge genetic manipulations or to draw conclusions about the cellular energy metabolism. Genome-scale metabolic flux analyses are carried out using the metabolite formation rates from a minimal number of cultivation experiments as additional constraints to prevent exhaustive wet experiments to provide realistic simulation results for better understanding of metabolic characteristics of a relatively unknown bacterium (Price et al., 2003; Galperin, 2004; Douglas et al., 2005; Smid et al., 2005; Christian et al., 2006).

\section{Genome-scale models}

Genome-scale models of microbial organisms, comprising different levels of information, are primarily on the stoichiometry of many different reactions (Price et al., 2003). Some information about metabolic regulation could offer a suitable platform for developing systems level tools for analyzing and engineering metabolism (Stephanopoulos et al., 2002; Patil et al., 2004; Douglas et al., 2005). These approaches currently enjoy limited applicability due to lack of kinetic and regulatory information on the whole genome scale (Kitano, 2002). Nevertheless, in the absence of kinetic and regulatory information, it is possible at least to partly predict the behavior of cellular metabolism using steady state analysis based on genome-scale stoichiometric models (Kitano, 2002; Douglas et al., 2005). OptKnock (Burgard et al., 2003) and OptStrain (Pharkya et al., 2004) search for a set of gene (reaction) deletions that maximize the flux towards a desired product, where the internal flux distribution is still operative in such a way that growth is optimized. Such identified key gene deletions will force a microorganism to produce the desired product in order to achieve maximal growth. The in silico model has also been used to predict the metabolic adaptation to several environmental perturbations including nitrogen limitation, electron acceptor limitation and phosphate limitation (Ibarra et al., 2002; dos Santos et al., 2003; Smid et al., 2005). These predictions are currently being compared with experimental data, including physiological measurements and global gene expression data, to achieve the goal of improvement in our understanding on the metabolism of microorganisms under non-optimal but environmentally relevant conditions (Arita, 2003; Regenberg et al., 2006).

\section{In silico analysis to experiments}

Metabolic flux analysis is very well suited for analysis of the effects of growth on different media (dos Santos et al., 2003a), specific mutations (dos Santos et al., 2003b), and screening of different mutants (Rhagavendran et al., 2004; Blank et al., 2005; Fisher and Sauer, 2005). Marcel et al. (2002) applied an integrated approach bringing kinetic modeling, metabolic control analysis and experimentation together for developing a rational strategy in genetic engineering. They optimized the metabolic flux in lactic acid bacteria, Lactococcus lactis, through the acetolactate synthase branch. Experimentally, the overall carbon flux was reduced by $11 \%$, however, this reduction was not as severe as the model had predicted. The major product formed was acetoin (50\% of the measured product formation rates), which was also in agreement with the model prediction. By introducing entire pathways, it is possible to produce known compounds more efficiently, to improve through combinatorial biosynthesis or to produce completely new chemical entities that may serve as possible new products, such as food ingredients, nutraceuticals or pharmaceuticals (Nielsen and Michael, 2008). Knowledge on intracellular fluxes is very crucial to understand cell metabolism. Out of it, bioreactor dynamic optimization schemes could be profited (Mahadevan et al., 2005). The data pertaining to RNA and metabolite composition using Affymetrix chips and GC-MS were interpreted statistically and also using computer simulations of a kinetic model built by merging two independent models of glycolysis and glycerol biosynthesis. According to Martins et al. (2004), the simulation results agree with the exponential growth phase data whereas no model is available for the post-diauxic phase.

Stelling et al. (2002) introduced so-called control effective fluxes, which are functions of the different elementary flux modes in the metabolic network, and showed that control effective fluxes correlate quite well with transcription in $E$. coli. In Saccharomyces cerevisiae, galactose uptake of several different mutants could be increased (80\%) through genomewide transcription analysis by over-expressing the pgm2 gene encoding phosphoglucomutase (Bro et al., 2005; 2006). Regenberg et al. (2004) performed transcriptome analyses of different specific growth rates in chemostat cultures (glucose limited) and identified specific genes responsible for either decreasing or increasing growth rates. While mapping all genes related to the Crabtree effect, genes responsible for catabolism of ethanol are transcribed at low specific growth rates. Basing this hypothesis, Escherichia coli uses its metabolism to grow at a maximal rate utilizing metabolically reconstructed MG1655 strain (Vemuri et al., 2002; 2007). Sang et al. (2005) correlated quantitative relationship among primary carbon source (acetate or succinate) uptake rate, oxygen uptake rate and maximal cellular growth rate through experimental formulations from in silico gene knock-out simulation. Thus, the stated hypothesis is consistent with experimental data.

The complete genome sequence of Mannheimia succiniciproducens MBEL55E explored the genome-scale metabolic characteristics leading to high-level succinic acid production (Hong et al., 2004). To improve its productivity, its central metabolic pathway was compared with that of $E$. coli for comparison to select important metabolic pathways for the formation of fermentation products (Lee et al., 2005). The results of in silico experiments suggested knocking out the ptsG, $p y k \mathrm{~F}$, and pykA genes that are the most beneficial to enhance production of succinic acid. Thus, a successful metabolic engineering of mutant $E$. coli W31 10GFA for enhanced succinic acid production (8-fold increase, 24 hrs, less glucose consumed) and a significant reduction of other fermentation products compared with the wild-type strain that could be achieved by combining genome and pathway comparison, in silico metabolic characterization, and validation by knockout experiments (Lee et al., 2002; 2005). Rational metabolic engineering based on known regulatory and metabolic information and new knowledge generated by transcriptome analysis combined with in silico simulation was carried out to develop an E. coli strain capable of overproducing 2.27-fold increase of L-valine achieved with VAMF (pKBRilvBNCED, pTrc184ygaZHlrp). This was as high as $0.378 \mathrm{~g}$ of L-valine/g glucose (Park et al., 2007). Thus, these results based on in silico genome-scale prediction of knockout targets are an efficient approach towards strain improvement in metabolic engineering. Hence, it is important 


\section{Journal of Computer Science \& Systems Biology - Open Access}

to combine the results of transcriptome profiling and in silico metabolic flux analysis, which are complementary to each other (Duarte et al., 2004; Regenberg et al., 2006; Rokem et al., 2007). Redirecting the metabolic flux towards such products without disturbing the overall cell physiology is a complex task. Nevertheless, metabolic footprinting will have applications in metabolic engineering (Douglas et al., 2005). The resulting data will contribute strongly in the generation and testing of mathematical models of cell behavior, whose iterative interplay with 'wet' experiments is the hallmark of systems biology (Ideker et al., 2001; Kitano, 2002). Most constraintbased metabolic models of microbial cells can take large-scale metabolite secretion into account (Reed and Palsson, 2003; Duarte et al., 2004). However, improved technical developments such as CE-MS, high-throughput LC-MS and multidimensional chromatography, including GC-TOF-MS, will enable wider coverage of the metabolomes, and make these measurements more straightforward and discriminatory (Plumb et al., 2003; 2004; Douglas et al., 2005).

\section{Current scenario of systems biotechnology}

Systems biotechnology is now in the early stages of development and presents a variety of technical challenges (Christian et al., 2006). Its central task is to comprehensively collect global cellular information, such as omics data, and to combine these data through metabolic, signaling and regulatory networks to generate predictive computational models of the biological system (Price et al., 2003; Patil et al., 2004; Smid et al., 2005). X-ome alone is insufficient to understand cellular physiology and regulatory mechanisms. Combined analysis will become more significant for better understanding of cellular physiology and metabolism at the systems level and to design strategies for metabolic and cellular engineering of organisms (Sang et al., 2005).

Advances in profiling methods, molecular genetics and the availability of genome sequence information for a wide variety of microbes have led to the development of integrated and flexible strain improvement platforms to rationally design microbes for the efficient production of commercially valuable metabolites. These approaches often benefit considering the advantages of the conventional mutation and screening efforts. More examples and insights of strain improvement through systems biotechnological research can be found in recent review (Stephanopoulos et al., 2004). A developing country could easily embark on this exciting and enterprising new research to assume leadership.

\section{Bio-products development}

In systems biotechnology, no single nation can explore all the promising ideas, for example, the case study done by Microbia, a Pharma company, in the production of statins, such as lovastatin and compactin, by optimizing fungal cellular processes. Statin-producing strains have displayed product yields (YP/S, g product/g carbohydrate) approaching 40\% of the theoretical yield in appropriately managed fermentations, rarely attained in the secondary metabolite fermentations. Applications of association analysis, regulator engineering and robust genetic selections to improve lovastatin production in Aspergillus terreus have been described elsewhere. These approaches have been combined with traditional metabolic engineering, and mutation and selection methods to enhance existing commercial processes and develop competitive strains from wild-type isolates (Askenazi et al., 2003).

Successful metabolic engineering of $E$. coli for the enhanced production of lysine, valine, and succinic acid could be achieved by combining genome and pathway comparison, in silico metabolic characterization, and validation by knockout experiments (Arita et al., 2003; Lee et al., 2005; Park et al., 2007). Metabolic flux balance has analyzed in Corynebacteria by genome based metabolic model for the production of lysine (Wittmann and Heinzle, 2001) and methionine (Ruckert, 2003). Smid et al. (2005) constructed metabolic models of Lactobacillus plantarum based on the availability of genome sequence information. Similarly, Askenazi et al. (2003) explained an integrating transcriptional and metabolite profile that is needed to direct the engineering of lovastatin-producing fungal strains. Further, they have focused to improve the methods and tools from genome sequence to gene annotation for pathway reconstruction and prediction of phenotype through metabolic models. Therefore, the exploitation of cellular complexity for strain improvement has been a challenging goal in applied biological research, as it requires the coordinated understanding of multiple cellular processes (Stephanopoulos et al., 2004). A current focus has also been on new genome-wide modeling approaches in functional genomics aimed at utilizing full advantage of genome sequence data, transcription profiling, proteomics and metabolite profiling for strain improvement.

\section{Conclusion}

Quantification of the metabolic network of an organism offers insights into possible ways of developing a mutant strain for better productivity of an extra-cellular metabolite. It is relevant to raise the question regarding the minimum number of accumulation rates of extra-cellular metabolites obtained through experiments, which are necessary for proper assessment of fluxes in a network (Kauffman et al., 2003). The improvement of cellular properties like viability or stress tolerance may be directly connected to overproduction of a desired biotechnological product. When sorting is used for the selection of over-producing cells, there are three main objectives: (1) to reduce the work load necessary to find over-producers, (2) to reduce the time required and (3) to find the cells with the highest possible production rates, ideally combined with other advantageous properties (Diethard and Nicole, 2006).

It can be used to alter the genotype, so that the phenotype exhibits cellular properties that are beneficial for the organisms utilized in industrial processes. Our ability to manipulate the cellular genotype to produce specific changes in the metabolic network outweighs our ability to rationally design the manipulations so that the desirable quantities are imparted to the organisms. In metabolic engineering, the integration of metabolomes data with fluxome and proteome data into largescale mathematical models promise to foster rational strategies for strain and cell line improvement (Schaub et al., 2006). Recent progresses in post-genomic biology allow addressing issues at the systems level by coupling the experimental with modeling approaches that constitute the core of systems biotechnology. In addition, advances in technology for generating various omics data and new computational methods should also help 
Citation: Chellapandi P, Sivaramakrishnan S, Viswanathan MB (2010) Systems Biotechnology: an Emerging Trend in Metabolic Engineering of Industrial Microorganisms. J Comput Sci Syst Biol 3: 043-049. doi:10.4172/jcsb.1000054

to overcome the existing limitations, and to make it possible to accelerate the development of systems biotechnology. Hypothesis-driven computational modeling or simulation and technology-driven high-throughput experimental analyses are combined to generate new knowledge via in silico and wet experiments in which in silico model and experimental design are continuously evolved during the iterations. The computational challenge for researchers is to integrate disparate data into models to infer useful biological knowledge, in order to enhance the biotechnological processes and to minimize the cost required for bioprocess engineering. Through this fast advances, fermentation media, microbial growth conditions, fermentation parameters and desired products with maximum yield, and low contaminated metabolites might be achieved with great potential. Computational systems biotechnology is, therefore, made a platform to experimental techniques for producing commodities with a low cost, good quality and quantity, and fastens the fermentation processes in industry.

\section{Acknowledgement}

The first author is grateful to the University Grants Commission, New Delhi, for financial assistance (UGC Sanction No. 32-559/2006) to carry out the work.

\section{References}

1. Arita M (2003) In silico atomic tracing by substrate-product relationships in Escherichia coli intermediary metabolism. Genome Res 13: 2455-2466. »CrossRef " PubMed " Google Scholar

2. Askenazi M, Driggers EM, Holtzman DA, Norman TC, Iverson S, et al. (2003) Integrating transcriptional and metabolite profiles to direct the engineering of lovastatin-producing fungal strains. Nat Biotechnol 21: 150-156. »CrossRef » PubMed " Google Scholar

3. Bennett JW, Laswre LL (1985) Genetic manipulations in fungi. Academic Press, Inc Harcourt Brace Jovonovich Publishers, New York. »CrossRef » PubMed » Google Scholar

4. Blank LM, Kuepfer L, Sauer U (2005) Large-scale 13C-flux analysis reveals mechanistic principles of metabolic network robustness to null mutations in yeast. Genome Biol 6: R49. " CrossRef » PubMed » Google Scholar

5. Bro C, Knudsen S, Regenberg B, Olsson L, Nielsen J (2005) Improvement of galactose uptake in Saccharomyces cerevisiae through overexpression of phosphoglucomutase: example of transcript analysis as a tool in inverse metabolic engineering. Appl Environ Microbiol 71: 6465-6472. »CrossRef » PubMed " Google Scholar

6. Bro C, Regenberg B, Forster, J Nielsen J (2006) In silico aided metabolic engineering of Saccharomyces cerevisiae for improved bioethanol production. Metab Eng 8: 102-111. »CrossRef » PubMed » Google Scholar

7. Burgard AP, Pharkya P, Maranas CD (2003) OptKnock: A bilevel programming framework for identifying gene knockout strategies for microbial strain optimization. Biotechnol Bioeng 84: 647-657. » CrossRef » PubMed » Google Scholar

8. Barrett CL, Kim TY, Kim HU, Palsson B $\varnothing$, Lee SY (2006) Systems biology as a foundation for genome-scale synthetic biology. Curr Opin Biotechnol 17: 488492. " CrossRef " PubMed " Google Scholar

9. Diethard M, Nicole B (2006) Review: Applications of cell sorting in biotechnology. Microbial Cell Factories 5: 12. »CrossRef » PubMed » Google Schola

10. dos Santos MM, Gombert AK, Christensen B, Olsson L, Nielsen J (2003a) Identification of in vivo enzyme activities in the cometabolism of glucose and acetate by Saccharomyces cerevisiae by using 13C-labeled substrates. Eukaryot Cell 2: 599-608. " CrossRef » PubMed " Google Scholar

11. Duarte NC, Herrgård MJ, Palsson $B \varnothing$ (2004) Reconstruction and validation of Saccharomyces cerevisiae iND750, a fully compartmentalized genome-scale metabolic model. Genome Res 14: 1298-1309. »CrossRef » PubMed » Google Scholar

12. Edwards JS, Ibarra RU, Palsson BO (2001) In silico predictions of Escherichia coli metabolic capabilities are consistent with experimental data. Nat Biotechnol 19: 125-130. »CrossRef » PubMed » Google Scholar

13. Fischer E, Sauer U (2005) Large-scale in vivo flux analysis shows rigidity and suboptimal performance of Bacillus subtilis metabolism. Nat Genet 37: 636-640. "CrossRef " PubMed " Google Scholar

14. Galperin MY (2004) Genomes back-to-back: when sequencing race is a good thing. Environ Microbiol 6: 1205-1209. " CrossRef » PubMed » Google Scholar

15. Hermann $T$ (2004) Using functional genomics to improve productivity in the manufacture of industrial biochemicals. Curr Opin Biotechnol 15: 444-448. "CrossRef » PubMed " Google Scholar

16. Hoefnagel MH, Starrenburg MJ, Martens DE, Hugenholtz J, Kleerebezem M, et al. (2002) Metabolic engineering of lactic acid bacteria, the combined approach: kinetic modelling, metabolic control and experimental analysis. Microbiol 148: 1003-1013. »CrossRef » PubMed » Google Scholar

17. Hong SH, Kim JS, Lee SY, In YH, Choi SS, et al. (2004) The genome sequence of the capnophilic rumen bacterium Mannheimia succiniciproducens. Nat Biotechnol 22: 1275-1281. »CrossRef » PubMed » Google Scholar

18. Ibarra RU, Edwards JS, Palsson BO (2002) Escherichia coli K-12 undergoes adaptive evolution to achieve in silico predicted optimal growth. Nature 420: 186189. »CrossRef » PubMed » Google Scholar

19. Ideker T, Galitski T, Hood L (2001) A new approach to decoding life: systems biology. Annu Rev Genomics Hum. Genet 2: 343-372. »CrossRef » PubMed » Google Scholar

20. Kauffman KJ, Prakash P, Edwards JS (2003) Advances in flux balance analysis. Cur Opin Biotechnol 14: 491-496. " CrossRef » PubMed " Google Scholar

21. Kell DB, Brown M, Davey HM, Dunn WB, Spasic I, et al. (2005) Metabolic footprinting and systems biology: The medium is the message. Nat Rev Microbiol 3: 557-565. »CrossRef » PubMed » Google Scholar

22. Kim J, Hongseak Y, Hyun UK, Hyung SC, Tae YK, et al. (2006) Resources for systems biology research. J Microbiol Biotechnol 16: 832-848. " CrossRef » PubMed " Google Scholar

23. Kirschner MW (2005) The meaning of systems biology. Cell 121: 503-504 "CrossRef " PubMed " Google Scholar

24. Kitano H (2002) Systems biology: a brief overview. Science 295: 1662-1664 "CrossRef » PubMed » Google Scholar

25. Lee SJ, Lee DY, Kim TY, Kim BH, Lee J, et al. (2005) Metabolic engineering of Escherichia coli for enhanced production of succinic acid, based on genome comparison and in silico gene knockout simulation. Appl Environ Microbiol 71 7880-7887. " CrossRef » PubMed » Google Scholar

26. Lee PC, Lee SY, Hong SH, Chang HN (2002) Isolation and characterization of a new succinic acid-producing bacterium, Mannheimia succiniciproducens MBEL55E, from bovine rumen. Appl Microbiol Biotechnol 58: 663-668. „ CrossRef » PubMed » Google Scholar

27. Mahadevan R, Burgard A, Famili I, Van Dien S, Schilling C (2005) Applications of metabolic modeling to drive bioprocess development for the production of valueadded chemicals. Biotechnol Bioprocess 10: 408-417. " CrossRef » PubMed " Google Scholar

28. Martins AM, Camacho D, Shuman J, Sha W, Mendes P, et al. (2004) A systems biology study of two distinct growth phases of Saccharomyces cerevisiae cultures. Curr Genomics 5: 649-663. "CrossRef » PubMed » Google Scholar

29. Moreira dos Santos M, Thygesen G, Kötter P, Olsson L, Nielsen J (2003b) Aerobic physiology of redox-engineered Saccharomyces cerevisiae strains modified in the ammonium assimilation for increased NADPH availability. FEMS Yeast Res 4: 59-68. " CrossRef » PubMed » Google Scholar

30. Nielsen J, Michael CJ (2008) Impact of systems biology on metabolic engineering of Saccharomyces cerevisiae. FEMS Yeast Res 8: 122-131. „CrossRef » PubMed " Google Scholar

31. Park JH, Lee KH, KimTY, Lee SY (2007) Metabolic engineering of Escherichia coli for the production of L-valine based on transcriptome analysis and in silico gene knockout simulation. PNAS 104: 7797-7802. »CrossRef » PubMed » Google Scholar

32. Patil KR, Akesson M, Neilsen J (2004) Use of genome-scale microbial models for metabolic engineering. Curr Opin Biotechnol 15: 64-69. »CrossRef » PubMed » Google Scholar

33. Patil KR, Rocha I, Forster J, Nielsen J (2005) Evolutionary programming as a platform for in silico metabolic engineering. BMC Bioinformatics 6: 308. » CrossRef » PubMed » Google Scholar

34. Peberdy JH, Ferenxy L (1985) Fungal protoplasts application in biochemistry 


\section{Journal of Computer Science \& Systems Biology - Open Access}

and genetics. Marcel Dekker, Inc. New York. "CrossRef » PubMed » Google Scholar

35. Pharkya P, Burgard, AP, Maranas CD (2004) OptStrain: a computational framework for redesign of microbial production systems. Genome Res 14: 2367 2376. » CrossRef » PubMed » Google Scholar

36. Plumb R, Castro-Perez J, Granger J, Beattie I, Joncour K, et al. (2004) Ultraperformance liquid chromatography coupled to quadrupole- orthogonal timeof-flight mass spectrometry. Rapid Commun Mass Spectrom 18: 2331-2337. "CrossRef » PubMed » Google Scholar

37. Plumb R, Granger J, Stumpf C, Wilson ID, Evans JA, et al. (2003) Metabolomic analysis of mouse urine by liquid-chromatography-time of flight mass spectrometry (LC-TOF-MS): detection of strain, diurnal and gender differences. Analyst 128: 819-823. » CrossRef » PubMed » Google Scholar

38. Price ND, Papin JA, Schilling CH, Palsson BO (2003) Genome-scale microbial in silico models: the constraints-based approach. TIBTEC 21: 162-169. » CrossRef » PubMed » Google Scholar

39. Raghavendran V, Gombert AK, Christensen B, Kotter P, Nielsen J (2004) Phenotypic characterization of glucose repression mutants of Saccharomyces cerevisiae using experiments with 13C-labelled glucose. Yeast 21: 769-779. »CrossRef » PubMed » Google Scholar

40. Reed JL, Palsson B $\varnothing$ (2003) Thirteen years of building constraint-based in silico models of Escherichia coli. J Bacteriol 185: 2692-2699. „ CrossRef » PubMed » Google Scholar

41. Regenberg B, Grotkjaer T, Winther O, Fausbøll A, Akesson M, et al. (2006) Growth-rate regulated genes have profound impact on interpretation of transcriptome profiling in Saccharomyces cerevisiae. Genome Biol 7: R107. "CrossRef " PubMed " Google Schola

42. Rokem JS, Lantz AE, Nielsen J (2007) Systems biology of antibiotic production by microorganisms. Nat Prod Rep 24: 1262-1287. » CrossRef » PubMed » Google Scholar

43. Rückert C, Pühler A, Kalinowski J (2003) Genome-wide analysis of the L-methionine biosynthetic pathway in Corynebacterium glutamicum by targeted gene deletion and homologous complementation. J Biotechnol 104: 213-228. "CrossRef » PubMed " Google Scholar

44. Lee SJ, Lee DY, Kim TY, Kim BH, Lee J, et al. (2005) Metabolic engineering of Escherichia coli for enhanced production of succinic acid, based on genome comparison and in silico gene knockout simulation. Appl Enniron Microbiol 71: 7880-7887. „CrossRef „PubMed „ Google Scholar
45. Sang YL, Dong YL, Tae YK (2005) Systems biotechnology for strain improvement TIBTEC 23: 1-7. » CrossRef » PubMed » Google Scholar

46. Schaub J, Schiesling C, Reuss M, Dauner M (2006) Integrated sampling procedure for metabolome analysis. Biotech Prog 22: 1434-1442. " CrossRef " PubMed » Google Scholar

47. Schuster S, Fell DA, Dandekar T (2000) A general definition of metabolic pathways useful for systematic organization and analysis of complex metabolic networks. Nat Biotechnol 18: 326-332. » CrossRef » PubMed » Google Scholar

48. Schwartz JM, Kanehisa M (2005) A quadratic programming approach for decomposing steady-state metabolic flux distributions onto elementary modes. Bioinformatics 21: ii204-ii205. » CrossRef » PubMed » Google Scholar

49. Smid EJ, van Enckevort FJ, Wegkamp A, Boekhorst J, Molenaar D, et al. (2005) A review: metabolic models for rational improvement of lactic acid bacteria as cell factories. J Appl Microbiol 98: 1326-1331. » CrossRef » PubMed » Google Scholar

50. Stelling J, Klamt S, Bettenbrock K, Schuster S, Gilles ED (2002) Metabolic network determines key aspects of functionality and regulation. Nature 420 190-193. » CrossRef » PubMed » Google Scholar

51. Stephanopoulos G (2002) Metabolic engineering by genome shuffling. Nat Biotechnol 20: 707-712. » CrossRef » PubMed » Google Scholar

52. Stephanopoulos G, Alper H, Moxley J (2004) Exploiting biological complexity for strain improvement through systems biology. Nat Biotechnol 22: 1261-1267. "CrossRef » PubMed » Google Scholar

53. Tomita M (2001) Whole-cell simulation: a grand challenge of the 21st century. TIBTECH 19: 205-210. » CrossRef » PubMed » Google Scholar

54. Vemuri GN, Eiteman MA, Altman E (2002) Effects of growth mode and pyruvate carboxylase on succinic acid production by metabolically engineered strains of Escherichia coli. Appl Environ Microbiol 68: 1715-1727. » CrossRef » PubMed » Google Scholar

55. Vemuri GN, Eiteman MA, McEwen JE, Olsson L, Nielsen J (2007) Increasing $\mathrm{NADH}$ oxidation reduces overflow metabolism in Saccharomyces cerevisiae. PNAS 104: 2402-2407. »CrossRef » PubMed » Google Scholar

56. Wittmann C, Heinzle E (2001) Modeling and experimental design for metabolic flux analysis of lysine-producing Corynebacteria by mass spectrometry. Metab Eng 3: 173-191. » CrossRef » PubMed » Google Schola 